\title{
CONCEITOS MULTIDIMENSIONAIS NA TERMINOLOGIA DA SENOLOGIA
}

Maria de Lurdes A. Garcia*

RESUMO: A existência de conceitos multidimensionais tem como reflexo certa proliferação vocabular nas linguagens científicas. Esses conceitos encerram em si inúmeros traços: uns originarão uma determinada verbalização, enquanto a predominância de outros produzirá outra actualização. Instala-se uma certa flutuação semântica e fenómenos de polissemia surgem naturalmente. Estes aspectos serão analisados neste artigo que aludirá também à investigação que temos realizado nas línguas de especialidade e que deu origem ao Dicionário Terminológico de Senologia, que apresentamos.

PALAVRAS-CHAVE: Conceitos multidimensionais; semantismo referencial; polissemia; harmonização; instrumentos terminográficos.

esde 1992 temos vindo a realizar investigação no Centro de Linguística da Universidade Nova de Lisboa, Linha de Investigação 2 - Lexicologia, Lexicografia, Terminologia, sob a orientação da Prof. Doutora Maria Teresa Lino. Tem sido dirigida à análise da língua de especialidade, ao estudo da terminogenia e aos processos conceptuais e referenciais suscitados pela fertilidade neonímica característica da linguagem científica.

O progresso científico e tecnológico origina proliferação vocabular, que determina, por um lado, a necessidade de se proce-

Universidade Nova de Lisboa, Portugal. 
der à harmonização de termos, de trazer ordem às terminologias e, por outro, impõe a necessidade de se precisar e fixar o sentido dos termos.

A Língua Portuguesa tem-se afirmado como língua de ciência e, no quadro da democratização do saber, torna-se necessário proceder à sua divulgação e também promover a sua aprendizagem. Para tal há que descrever as linguagens científicas e preparar os instrumentos pedagógico-didácticos adequados.

Tendo a nossa investigação sido orientada para a linguagem científica, na área da Medicina, observámos que os conceitos, na generalidade, são multidimensionais. Encerram em si inúmeros traços conceptuais: uns originarão uma determinada verbalização, enquanto que a predominância de outros traços produzirá outra actualização. Assim, determinados caracteres conceptuais são responsáveis por alterações semânticas, em virtude da perspectiva em que o conceito é considerado. Por exemplo, em Senologia, ramo das ciências médicas que tem como objecto: "a abordagem multidisciplinar da mama e da sua patologia em áreas tão distintas como a investigação básica ou clínica, a prevenção ou o rastreio, o diagnóstico ou o tratamento, enfim a reabilitação ou os cuidados terminais" (Conde,1989), assiste-se a uma enorme proliferação terminológica.

A Senoterminologia resulta não só do desenvolvimento científico da Senologia e de uma especialização cada vez maior que origina formulação e reformulação de conceitos, mas também de uma grande variedade de situações comunicativas interactuantes, pelo facto de a Senologia ser uma área do conhecimento em que se verifica uma transversalidade e conexão entre as várias áreas temáticas: anatomopatologia, imagiologia, clínica, cirurgia, medicina nuclear, oncologia médica, psico-oncologia, reabilitação..., cada uma com um campo de investigação circunscrito e particular e recorrendo a diferentes metodologias que permitem perspectivas próprias para o estudo das mesmas lesões. 
A evolução e o desenvolvimento científico, a maior especialização do conhecimento, a formulação e reformulação de conceitos (vulgarização), a transversalidade e conexão das várias áreas temáticas, a variedade de situações comunicativas interactuantes originam conceitos multidimensionais e proliferação terminológica. Relativamente a um termo, instala-se um conflito linguístico suscitado por perturbação semântica devida aos inúmeros traços conceptuais que ele contém. A flutuação semântica determina alternância de verbalização, ambiguidade lexical e instabilidade terminológica, que os utilizadores desta terminologia desejam solucionar.

Em virtude das metodologias usadas e das especificidades das lesões, o Especialista, como atrás se referiu, pode dar preponderância a determinados traços conceptuais que originarão uma determinada verbalização, enquanto a predominância de outros traços produzirá outra actualização. Assim, determinados caracteres conceptuais são responsáveis por alterações semânticas, em virtude da perspectiva em que o conceito é considerado. Essa possibilidade de representações diferentes origina inevitavelmente fenómenos de polissemia. Igualmente, a reconceptualização de conceitos originada pela evolução científica contribui também para que o conflito linguístico se avolume.

A comunidade científica vai tentando solucionar estes fenómenos caso a caso. No entanto sente necessidade de instrumentos de referência para a sua terminologia, bem como de proceder à harmonização dos termos. Deste modo, para a concretização deste objectivo, a Sociedade Portuguesa de Senologia manifestou interesse em constituir uma equipa de trabalho de Especialistas de Senologia, nacionais e estrangeiros, na sua maioria Professores Universitários, apoiados por Linguistas, no caso vertente a autora, membro da equipa de investigação em Lexicologia, Lexicografia do Centro de Linguística da FCSH - Universidade Nova de Lisboa.

Havia assim que proceder ao trabalho de explicitação e fixação da significação dos termos para a harmonização pretendida. 
Deste modo, com base numa intenção descritiva da Terminologia da Senologia e para o estudo da problemática da instabilidade terminológica e da sua desejada harmonização, procedeu-se a uma pesquisa documental para constituição do corpus de análise da Terminologia da Senologia.

Na óptica da filosofia de um corpus evolutivo, privilegiámos o contacto com o meio científico e sua colaboração - (Sociedade Portuguesa de Senologia e seu Conselho Consultivo). A compilação do acervo documental foi aconselhada e orientada por Especialistas das várias áreas de aplicação relativas à Senologia. Reunimos um corpus composto por recursos textuais multilingues em português, espanhol, francês e inglês, resultante de uma selecção bibliográfica e textual rigorosa e muito actualizada de obras de referência, de carácter geral relacionadas com a história do cancro em Portugal com objectivo informativo, obras de vulgarização relacionadas com o cancro da mama, revistas, artigos, índices e outras de natureza dicionarística, enciclopédica e pedagógico-didáctica, abrangendo uma representatividade das diversas especialidades interactuantes na Senologia.

Procedeu-se à informatização de todo o corpus. As Novas Tecnologias da Informação constituíram um apoio e recurso de importância fundamental neste trabalho de informatização, do seu alargamento e enriquecimento, de exploração textual e de análise terminológica.

As facilidades proporcionadas pela web constituem um auxiliar multimedia precioso no apoio à investigação realizada por um terminólogo. Trazem uma mais valia de rapidez, acrescida de menor possibilidade de erro e de maior rigor em relação à pesquisa manual, aspectos de extraordinária importância que, sem dúvida, facilitam o trabalho terminológico e terminográfico e se traduzem numa produção dicionarística de maior volume e qualidade.

Com as Novas Tecnologias da Informação e Comunicação e pesquisa na Internet, o trabalho terminológico tem adquirido uma dimensão alargada que as potencialidades dessa tecnologia lhe ofe- 
recem, com a disponibilidade em diversos sites de um volume quase infinito de dados multilingues.

Os motores de busca automática são auxiliares, cada vez mais fiáveis e rápidos, que permitem, em poucos segundos, localizar um termo, organizar e analisar a sua rede conceptual, apreender o seu sentido pelo seu contexto, ou mesmo conseguir a sua definição, o seu equivalente noutra língua etc.

A interactividade que a web proporciona é também um aspecto importante a considerar na pesquisa terminológica pelo enorme apoio que dispensa ao terminólogo em foruns de discussão especializados, de conversação em tempo real, de constituição de listas de difusão via e-mail, que permitem um intercâmbio entre os interessados, conduzindo à obtenção de informações de valor relevante na área de pesquisa.

A pesquisa na Internet proporcionou-nos uma informação e uma actualização permanentes sobre toda a publicação recente na Senologia, facultou ainda acesso a alguns glossários multilingues que, na óptica de um corpus evolutivo, enriqueceram o nosso corpus e nos permitiram alargar a investigação. $\mathrm{O}$ alargamento do corpus proporcionou-nos a identificação de novos termos e equivalentes em espanhol, francês e inglês, permitiu-nos a aquisição de conhecimentos necessários à descrição dos termos, complementando informações indispensáveis à redacção de definições.

Todo este trabalho foi realizado em equipa com Especialistas de Senologia, portugueses e estrangeiros e apoiado pela sociedade portuguesa de Senologia. Foi assim enriquecido com a complementaridade das competências dos intervenientes: $\mathrm{O}$ Senologista, conhecedor do domínio científico, fornece informações relativas à especificidade dos termos e indica as carências sentidas. O Especialista alerta para situações de conflito linguístico motivadas por uma grande fertilidade neonímica e explicita os mecanismos conceptuais e linguísticos que os criadores de uma Terminologia accionam no processo semântico-lexical. Faculta um melhor entendimento do processo relacional entre o não linguístico e o 
linguístico, entre um conceito e o que ele representa e ajuda a clarificar e precisar o semantismo referencial. São condições que julgamos de primeira importância no processo terminogénico e que dependem de um processo mental, psico-linguístico e social complexo, proporcionando assim uma melhor compreensão e consciencialização das questões de instabilidade, identificadas na Terminologia da Senologia.

O Terminólogo investiga e estuda as questões terminológicas a que deverá dar resposta, analisa a sua dinâmica, as tendências mais frequentes na sua terminogénese e procura identificar os mecanismos linguísticos a ser considerados na resolução de casos de instabilidade, no sentido de uma harmonização de termos que possam optimizar o acto comunicativo e propiciar um melhor entendimento entre os utilizadores desta Língua de especialidade.

No quadro da gestão documental dos textos compilados e constitutivos do corpus, a nossa opção privilegiou uma análise essencialmente qualitativa dos textos, dado que constituem o melhor testemunho do ambiente de criação, descrição e de denominação de conceitos novos.

O corpus originou uma Base de Dados Textual informatizada, que permitiu a realização de diversas pesquisas que possibilitaram acesso muito rápido a informação semântica e linguística actualizada.

Esta Base de Dados, além de permitir a execução rápida de pesquisas, facultou maior rigor nas análises efectuadas. Proporcionou acesso a um número muito maior de exemplos que puderam ser examinados no seu ambiente contextual real e que contribuíram para uma identificação mais precisa dos traços semânticos referenciais das unidades senoterminológicas. Permitiu recolha rápida de informações e apoiou a realização de diversos tipos de pesquisa terminológica automática a partir do corpus textual, como extracção de unidades terminológicas quase transparentes na língua portuguesa, espanhola, francesa e inglesa, isto é, "internacionalismos" terminológicos; pesquisa de formantes que justificam a frequência de internacionalismos na Terminologia Senológica, bem 
como a sua produtividade; listagem de formantes que entram na constituição da Senoterminologia e que a caracterizam; extracção de contextos de termos e de formantes - contextos de substância relativamente aos termos e contextos mais formais, evidenciando as particularidades morfossemânticas dos formantes; pesquisa de definições em português, espanhol, francês e inglês, que eventualmente podem permitir verificar a coincidência das definições, ou algumas particularidades semânticas relativas às diversas conceptualizações existentes em cada uma das línguas; estudo de equivalentes em espanhol, francês e inglês; extracção de coocorrentes que evidenciam colocações, tanto de termos, como de formantes em cada uma das línguas; verificação da aceitabilidade fácil de termos estrangeiros ("internacionalismos") em consequência da motivação semântica e da transparência dos seus formantes greco-latinos; observação da implantação fácil de internacionalismos, apesar da adaptação fonológica e morfossintáctica portuguesa; realização de estudo comparativo de diversos aspectos terminológicos da Senoterminologia.

A realização das diversas pesquisas e o trabalho conjunto do par especialista- terminólogo deram origem ao Dicionário Terminológico de Senologia, cuja nomenclatura e definições foram verificadas e validadas por consenso entre os Senologistas que integraram a equipa. É um produto que poderá constituir um ponto de partida para o trabalho de estabilização desta língua de especialidade.

É um dicionário elaborado de acordo com os princípios da "Nova Lexicografia" (B. Quemada) e com recurso às Novas Tecnologias. $\mathrm{O}$ ambiente tecnológico da Sociedade da Informação influenciou todas as etapas do nosso percurso e beneficiou não só a pesquisa, como a concretização deste projecto dicionarístico, a sua difusão e a sua permanente actualização.

É um dicionário plurilingue: com 2.045 entradas em português e equivalentes em espanhol, francês e inglês, com informações de carácter linguístico e conceptual relativas a cada um dos termos. 
O repertório dos termos dicionarizados foi decidido em função do uso na esfera de actividade da Senologia e funcionará como um instrumento de referência, um guia, um auxiliar de eficácia comunicativa na área da Senologia.

É um trabalho de grande interesse para um público vasto: especialistas do domínio e de outras áreas conexas, tradutores, redactores técnicos, estudantes da língua de especialidade e até público em geral.

A título exemplificativo, observe-se a imagem de uma página deste dicionário:

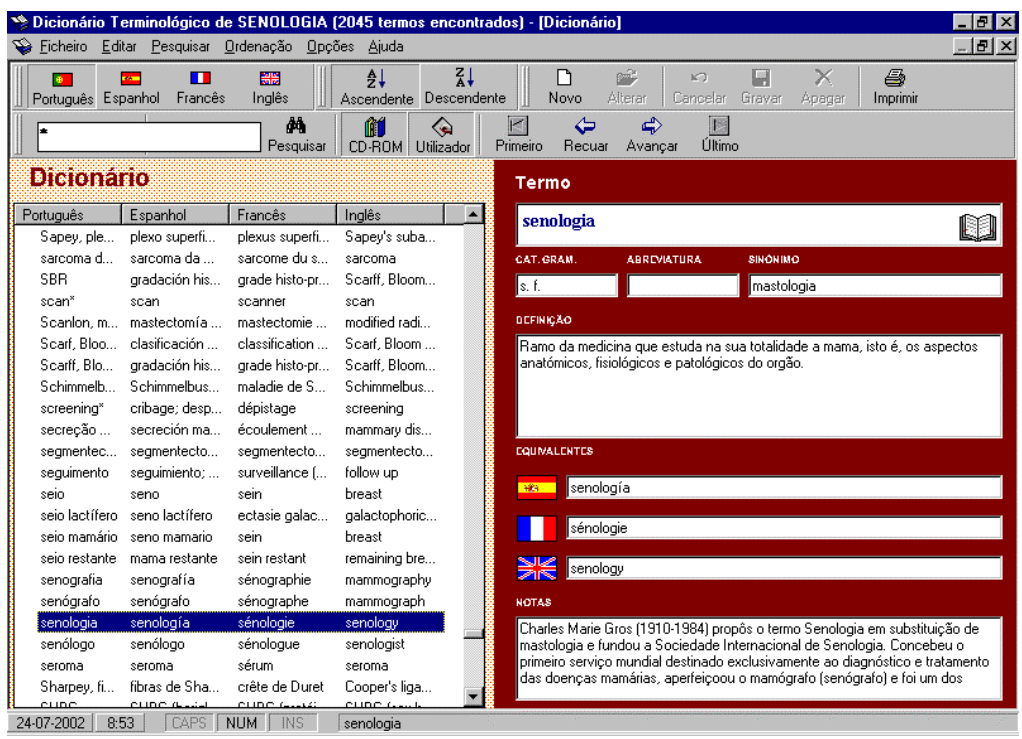

Este dicionário foi produzido em CD-Rom, mas também é possível a sua consulta onlineatravés dos sites da Universidade Nova de Lisboa - FCSH (www.unl.pt) e da Sociedade Portuguesa de Senologia (www.spsenologia.pt).

Como instrumento interactivo, este Dicionário é dotado de uma dinâmica operatória e o potencial do seu software é polivalente. Permite executar operações diversas de pesquisa, visualização, consulta e edição. 
Oferece ao utilizador a possibilidade de realizar pesquisas múltiplas em função das interrogações que lhe colocar e dos problemas que pretenda resolver. Por exemplo, auxilia a precisar o sentido dos termos, facilita a análise e comparação dos diversos sinónimos existentes, ajuda a referenciar numa série sinonímica qual o termo a privilegiar para a expressão de um determinado conceito, permite identificar o equivalente estrangeiro (espanhol, francês e inglês), pesquisar e fazer uma listagem de todos os termos com um determinado elemento de formação: oma; ose; anti etc., com um determinado núcleo: carcinoma, calcificações etc., com um determinado elemento em posição inicial, central ou final. Permite o estudo comparativo de diversos equivalentes de acordo com o objectivo definido, enfim, possui inúmeras potencialidades de grande utilidade para a comunicação a nível internacional, bem como para os trabalhos de estabilização terminológica neste domínio, também em curso a nível internacional.

Accionando a funcionalidade do Dicionário do Utilizador, contida na sua programação, a dinâmica operatória deste dicionário permite ainda anotar comentários, apresentar propostas, efectuar alterações, expansões num quadro de actualização permanente, baseada no consenso participativo dos Especialistas e Linguistas.

Em linhas gerais, esse Dicionário tem como grandes objectivos dotar a Comunidade Portuguesa de um instrumento de referência na linguagem médica e apoiar o estudo desta Língua de Especialidade. Funciona como um meio de comunicação, como um "media" cultural ao serviço da difusão da informação - formação e contribui também para a estabilização da Terminologia da Senologia.

Possibilitando a análise dos traços multidimensionais dos conceitos e da especificidade das suas particularidades semânticas, ambiciona vir a ser um contributo para a solução de questões polissémicas resultantes da transversalidade e conexão entre as várias áreas temáticas desta especialidade, no sentido da resolução dos seus conflitos linguísticos. 
GARCIA, Maria de Lurdes A. Conceitos multidimensionais na terminologia da senologia

Pelas suas características terminológicas e terminográficas, pretende também poder constituir um modelo para a produção de instrumentos pedagógico-didácticos idênticos, necessários à aprendizagem de uma língua em geral e, em particular, de uma língua de especialidade.

\section{BIBLIOGRAFIA}

ALVES, I. M. (1994) La synonymie en intelligence artificielle. Méta, 39, 4, p. 643-50.

DEPECKER, L. (2002) Entre signe et concept - Éléments de terminologie générale. Paris: Presses Sorbonne Nouvelle.

FUCHS, C.; ROBERT, S. (1997) Diversité des langues et représentations cognitives. Paris: Editions Ophrys.

GARCIA, M. de L. (2006) Dicionário terminológico de Senologia. CD-Rom. Lisboa: FCSH-UNL e SPS.

(2003) O semantismo referencial nos processos terminogénicos da Terminologia da Senologia. Dissertação (Doutoramento) - Universidade Nova de Lisboa.

. (2003) Língua de Especialidade: Terminogenia e o papel dos especialistas. TERMINOLOGIA DE OUTONO, ILTEC. Lisboa: Faculdade de Letras da Universidade Clássica de Lisboa.

KLEIBER, G. (1999) Problèmes de sémantique - La polysémie en questions. Paris: P.U. Septentrion.

LAKOFF, G. (1997) Les universaux de la pensée métaphorique: variations dans l'expression linguistique. In: Diversité des langues et représentations cognitives. Paris: Editions Ophrys. REY-DEBOVE, J. (1998) La linguistique du signe - Une approche sémiotique du langage. Paris: Armand Colin. (1997) Le métalangage. Paris: Armand Colin. (1989) Prototypes et définitions. DRLAV, 41, p. 143-67.

ABSTRACT: The existence of multidimensional concepts is reflected in the proliferation of vocabulary in scientific language. Such concepts incorporate numerous traits, some of which will lead to one verbalization while others will lead to a different one. One is therefore faced with semantic variability and related phenomena. Such aspects will be analyzed in this paper, which will also refer to the research we have carried out in specialized language, leading to the development of our Terminological Dictionary of Senology.

KEYWORDS: Multidimensional concepts; referential semantism; polisemy; harmonisation; terminographic tools. 